\title{
Probucol alleviates atherosclerosis and improves high density lipoprotein function
}

\author{
Jian-Kai Zhong, Zhi-Gang Guo ${ }^{*}$, Chen Li, Zhen-Kun Wang, Wen-Yan Lai and Yan Tu
}

\begin{abstract}
Background: Probucol is a unique hypolipidemic agent that decreases high density lipoprotein cholesterol (HDLC). However, it is not definite that whether probucol hinders the progression of atherosclerosis by improving HDL function.

Methods: Eighteen New Zealand White rabbits were randomly divided into the control, atherosclerosis and probucol groups. Control group were fed a regular diet; the atherosclerosis group received a high fat diet, and the probucol group received the high fat diet plus probucol. Hepatocytes and peritoneal macrophages were isolated for $\left[{ }^{3} \mathrm{H}\right]$ labeled cholesterol efflux rates and expression of ABCA1 and SR-B1 at gene and protein levels; venous blood was collected for serum paraoxonase 1, myeloperoxidase activity and lipid analysis. Aorta were prepared for morphologic and immunohistochemical analysis after 12 weeks.

Results: Compared to the atherosclerosis group, the paraoxonase 1 activity, cholesterol efflux rates, expression of $A B C A 1$ and SR-BI in hepatocytes and peritoneal macrophages, and the level of ABCA1 and SR-BI in aortic lesions were remarkably improved in the probucol group, But the serum HDL cholesterol concentration, myeloperoxidase activity, the IMT and the percentage plaque area of aorta were significantly decreased.
\end{abstract}

Conclusion: Probucol alleviated atherosclerosis by improving HDL function. The mechanisms include accelerating the process of reverse cholesterol transport, improving the anti-inflammatory and anti-oxidant functions.

Keywords: probucol, high density lipoprotein function, reverse cholesterol transport, Paraoxonase 1,

Myeloperoxidase

\section{Background}

Numerous epidemiological studies reported an inverse relationship between high density lipoprotein cholesterol (HDL-C) and the incidence of cardiovascular disease. The national cholesterol education program adult treatment panel III guidelines identified that low HDL-C $(<40$ $\mathrm{mg} / \mathrm{dl}$ ) is a major risk factor for coronary heart disease (CHD), independent of triglycerides and total cholesterol; for every $1 \mathrm{mg} / \mathrm{dl}$ increase in HDL-C, the predicted incidence of coronary events decreases by $2 \%$ in men and $3 \%$ in women $[1,2]$.

However, the relationships between HDL and CHD risk are more complex beyond the serum HDL-C levels. The Milano people who carry the apolipoprotein A-I Milano mutant have low serum HDL-C levels but do not

\footnotetext{
* Correspondence: guozhigang126@126.com

Division of Cardiology, Nanfang Hospital, Southern Medical University, Guangzhou 510515, Guangdong, P.R. China
}

confer an increased cardiovascular risk [3]. Additionally, the torcetrapib, an inhibitor of potent cholesteryl ester transfer protein (CETP), markedly increased the serum HDL-C levels, but the risk of deaths and cardiac events had been increased simultaneously in patients receiving tocetrapib [4]. Hausenloy and his colleagues found that HDL isolated from patients with CHD was ineffective as an antioxidant, but paradoxically, appeared to be prooxidant [5]. Given this complexity, it is not surprising that a single assay of serum steady-state HDL-C levels does not necessarily correlate with HDL function. Structural modification and composition alteration of HDL may lead to HDL loss of normal biological function, even though HDL-C levels is normal which still failed to inhibit atherosclerosis.

Probucol is a unique cholesterol lowering drug with anti-oxidant and anti-inflammatory properties that decreases HDL-C levels [6]. Multivitamins and probucol
C Biomed Central

(c) 2011 Zhong et al; licensee BioMed Central Ltd. This is an Open Access article distributed under the terms of the Creative Commons Attribution License (http://creativecommons.org/licenses/by/2.0), which permits unrestricted use, distribution, and reproduction in any medium, provided the original work is properly cited. 
(MVP) trial revealed that probucol reduces coronary restenosis after percutaneous transluminal coronary angioplasty [7]. And probucol observational study illuminating therapeutic impact on vascular events (POSITIVE) showed that probucol was useful in lowering the risk of cardiovascular events in secondary prevention in spite of causing a decrease in HDL-C levels [8]. Although probucol decreases HDL-C levels, it shows greatly controlled progression of atherosclerosis. We concluded that probucol may improve HDL function.

The major cardiovascular protective effects of HDL function may be attributed to its role in reverse cholesterol transport (RCT), anti-oxidant and anti-inflammation and so on [9]. ATP binding cassette transporter A1 (ABCA1) and scavenger receptor class $\mathrm{B}$ type I (SR-BI) play the key role in the process of RCT, high expression of $A B C A 1$ and SR-BI can reflect the atheroprotective function of HDL [10]. So we examined whether probucol promoted RCT by up-regulating the expression of ACBA1 and SR-BI in peritoneal macrophages and hepatocytes. Paraoxonase 1 (PON1) and Myeloperoxidase (MPO) are enzymes closely associated with HDL anti-oxidant function. PON1 contributes to the anti-oxidant effects of HDL and its activity is inversely related to the risk of cardiovascular diseases [11]. MPO participates in HDL-oxidation and its activity is positive correlation with the risk of cardiovascular diseases [12]. And we considered probucol may improve HDL anti-oxidant function by affecting serum PON1 and MPO activity.

\section{Results}

Effects of probucol on serum lipid and body weight

There were no significant difference in serum lipid levels and body weight among the three groups at the baseline. At the end of the research, the results of the serum lipid suggested that hypercholesterolemia model was successfully established, serum triglyceride (TG), total cholesterol (TC), LDL-C and HDL-C in atherosclerosis group were significantly higher than control group. Serum lipids were also increased in probucol group as compared with control group, but TC, LDL-C and HDL-C in probucol group were significantly lower than atherosclerosis group. There was no doubt that probucol reduced HDL quantity. There was no significant difference in body weight among the three groups throughout the experiment (Table 1).

\section{Effects of probucol on restraining aortic atherosclerosis}

The thoracic aortic IMT and the percentage plaque area (surface area of plaque/surface area of whole intima) were significantly higher in the two cholesterol-fed groups than control group, which indicated that the expected atherosclerotic model were successful. Additionally, IMT and the percentage plaque area in probucol group were lower than atherosclerosis group, which revealed that probucol hindered the process of atherosclerosis (Figure 1).

\section{Effects of probucol on cholesterol efflux rate in hepatocytes and peritoneal macrophages}

We measured the HDL-induced cholesterol efflux rate in hepatocytes and peritoneal macrophages. The results showed that the cholesterol efflux rate of hepatocytes and peritoneal macrophages in atherosclerosis group were about half of control group. However, cholesterol efflux rate of hepatocytes and peritoneal macrophages in probucol group were about two-fold higher than atherosclerosis group. (Figure 2)

\section{$A B C A 1$ or SR-BI mRNA and protein expressions in hepatocytes or peritoneal macrophages}

We found that mRNA expressions of ABCA1 and SR-BI in hepatocytes were significantly lower in atherosclerosis group than in control group, but they were significantly higher in probucol group than in atherosclerosis group. Furthermore, the result also showed that mRNA

Table 1 Serum lipid and body weight profiles in three groups' rabbits

\begin{tabular}{lccccc}
\hline & TG & TC & LDL-C & HDL-C & BW(kg) \\
\hline Control group & & & & & \\
0 week & $1.04 \pm 0.19$ & $1.85 \pm 0.12$ & $1.00 \pm 0.20$ & $0.47 \pm 0.12$ & $2.01 \pm 0.08$ \\
12 week & $1.02 \pm 0.15$ & $1.79 \pm 0.21$ & $1.09 \pm 0.23$ & $0.45 \pm 0.12$ & $2.77 \pm 0.04$ \\
Atherosclerosis group & & & & & \\
0 week & $1.10 \pm 0.14$ & $1.77 \pm 0.15$ & $0.99 \pm 0.20$ & $0.48 \pm 0.12$ & $2.07 \pm 0.06$ \\
12 week & $1.58 \pm 0.25^{*}$ & $23.26 \pm 3.30^{*}$ & $18.09 \pm 4.04^{*}$ & $1.11 \pm 0.09^{*}$ & $2.88 \pm 0.08$ \\
Probucol group & $1.02 \pm 0.15$ & $1.76 \pm 0.11$ & $1.00 \pm 0.15$ & $0.43 \pm 0.10$ & $2.03 \pm 0.04$ \\
0 week & $1.60 \pm 0.17$ & $16.70 \pm 0.70^{\#}$ & $13.79 \pm 2.01^{\#}$ & $0.51 \pm 0.06^{\#}$ & $2.72 \pm 0.21$ \\
12 week & & & & & \\
\hline
\end{tabular}

TC, total cholesterol; LDL-C, low-density lipoprotein cholesterol; TG, triglyceride; HDL-C: high-density lipoprotein cholesterol; BW: body weight. Units for TC, TG, $\mathrm{LDL}-\mathrm{C}$ and $\mathrm{HDL}-\mathrm{C}$ are $\mathrm{mmol} / \mathrm{L}$ and $\mathrm{BW}$ is $\mathrm{kg}$. All values are presented as mean \pm S.D. $(\mathrm{n}=6)$.

${ }^{*} \mathrm{P}<0.05$, compared to control group; ${ }^{\#} \mathrm{P}<0.05$, compared to atherosclerosis group. 


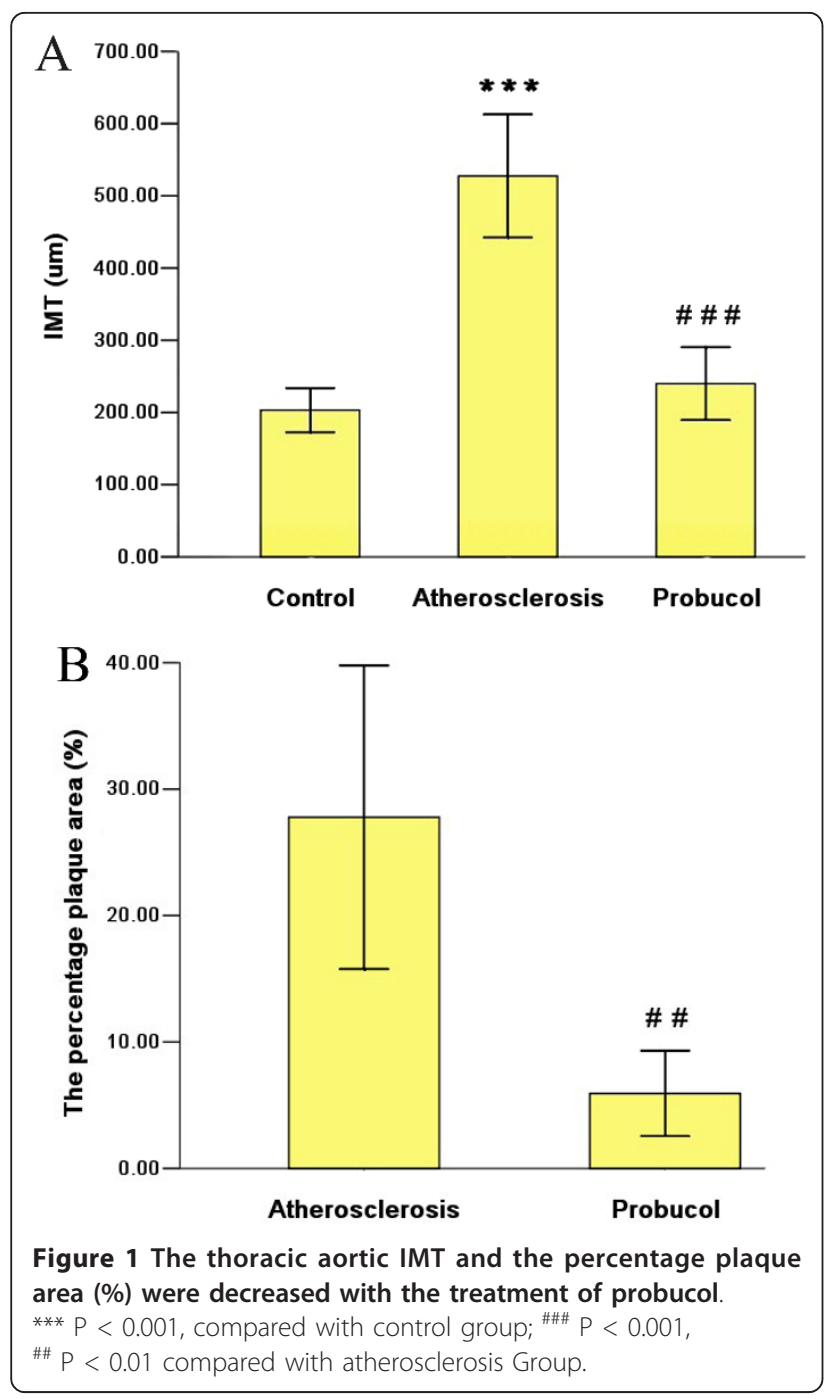

expression of SR-BI was higher than ABCA1 in hepatocytes (Figure 3A).

At the same time, we measured ABCA1 and SR-BI protein expressions in hepatocytes and peritoneal macrophages. The results showed that ABCA1 and SRBI protein expressions in probucol group both in hepatocytes and peritoneal macrophages were higher than in atherosclerosis group. More interesting, we found that protein expression of ABCA1 was higher than SR$\mathrm{BI}$ in peritoneal macrophages, but expression of SR-BI was higher than ABCA1 in hepatocytes. Furthermore, we observed that as compare with atherosclerosis group, protein expressions of ABCA1 in hepatocytes and peritoneal macrophages on probucol group were increased by $44.96 \%$ and $52.15 \%$ respectively; and SR$\mathrm{BI}$ in hepatocytes and peritoneal macrophages on probucol group were increased by $98.14 \%$ and $79.92 \%$, respectively (Figure 3B-C).

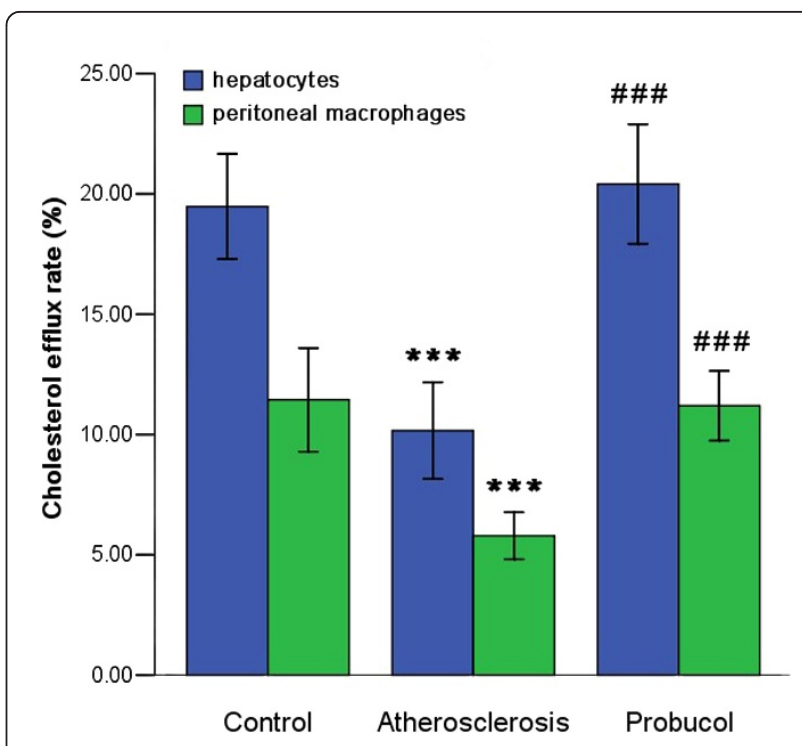

Figure $\mathbf{2}$ Cholesterol efflux rate of hepatocytes and peritoneal macrophages were increased in probucol group. ${ }^{* * *} \mathrm{P}<0.001$, compared with control group; ${ }^{\# \# ~} P<0.001$, compared with atherosclerosis group.

Immunohistochemical localization of $A B C A 1$ and SR-BI in Aortic atherosclerosis lesions

In the control group, there were no atherosclerosis plaques and immunohistochemical staining in aortic walls for ABCA1 and SR-B1. So we just analyzed the percentage of the positive area in the two cholesterol-fed groups. As shown in the Figure 4, ABCA1 (deep brown) and SR-B1 (deep red) protein could be detected in aortic atherosclerosis plaques. We found that ABCA1 and SR-BI protein positive area were significantly higher in probucol group than in atherosclerosis group (Figure 4C).

\section{Effects of probucol on serum PON1 and MPO activity}

To study the effect of probucol on anti-oxidant and anti-inflammation properties of HDL, we detected the serum PON1 and MPO activity. Compared with the control group, the serum PON1 activity was extremely lower in atherosclerosis group, and serum PON1 activity was significantly increase when treated by probucol. In addition, extremely low MPO activity was found in the samples obtained from control group, and the MPO activity in atherosclerosis group showed significantly higher in comparison to the probucol group (Figure 5).

\section{Discussion}

The most important theory revolved around the role of HDL function is RCT, in which excess cholesterol effluxes to HDL and ultimately returns to the liver for metabolism. The process of RCT is extremely complicated: At first, cholesterol efflux from macrophages and then lipid-poor ApoA-I quickly acquires it via the 


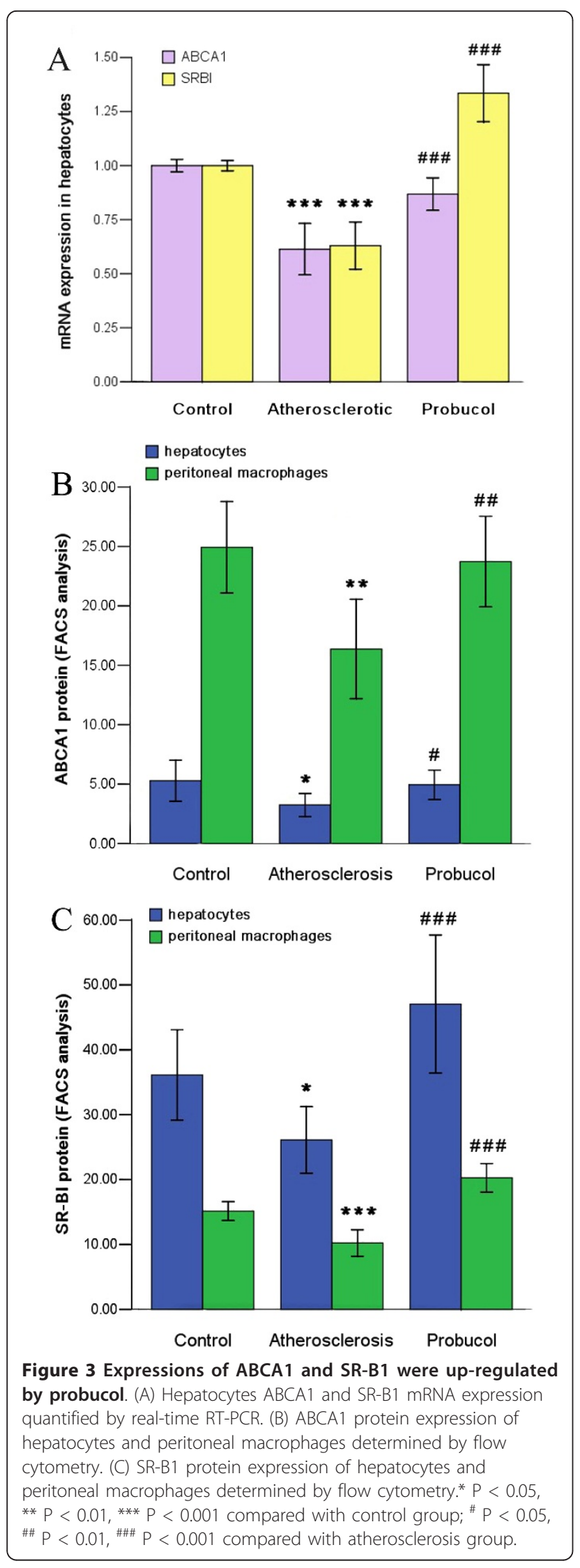

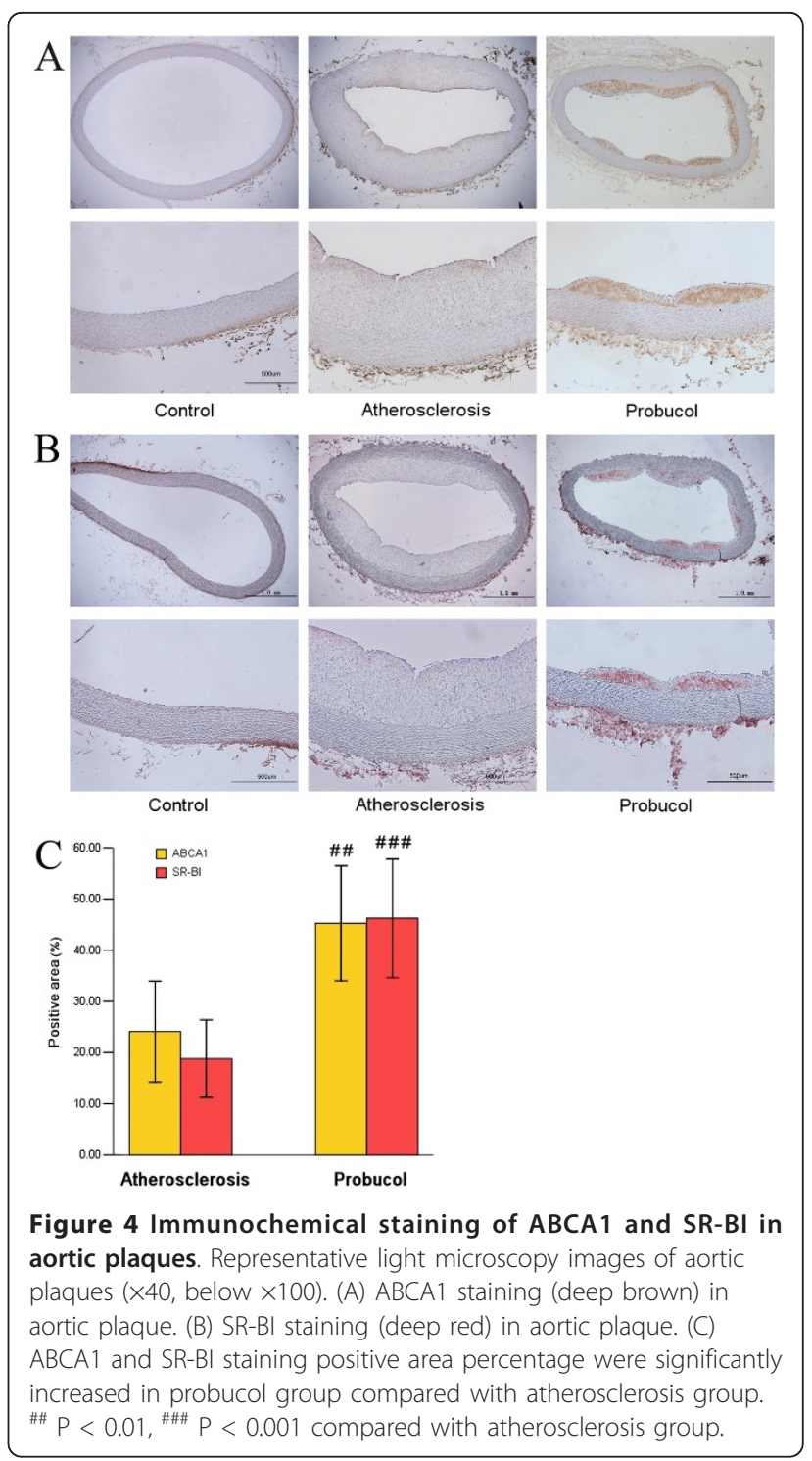

ABCA1 transporter. Lipidation of the lipid-poor ApoA-I and cholesterol complex generates nascent (pre- $\beta$ ) HDL [13]. Subsequently, lecithin cholesterol acyl transferase (LCAT) mediated cholesterol esterification generates small $\mathrm{HDL}_{3}$ particles; small $\mathrm{HDL}_{3}$ can be converted to large mature $\mathrm{HDL}_{2}$ in turn upon CETP [14]. At last, these mature $\mathrm{HDL}_{2}$ transfer its cholesterol to the liver directly via SR-BI and excrete cholesterol through the bile (Figure 6) [15].

The best-recognized atheroprotective function of HDL is the promotion of cholesterol efflux from cells, particularly from macrophages and hepatocytes, because macrophages are the primary cell type to accumulate cholesterol within the atherosclerotic plaque and hepatocytes are the main cell type to excrete cholesterol through the bile [16]. In our research, we found that probucol increased the cholesterol efflux capacity of 


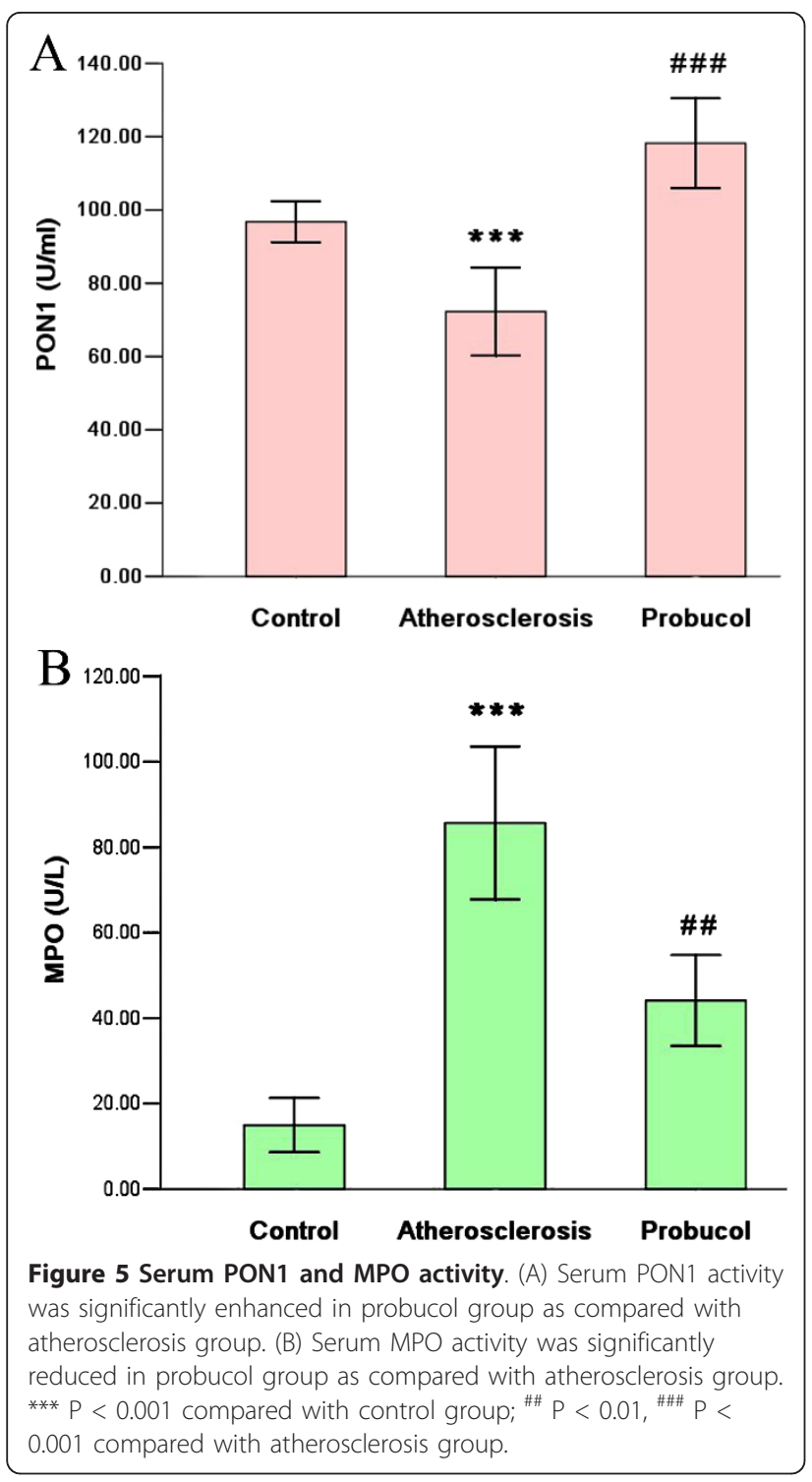

peritoneal macrophages, which could accelerate cholesterol effusing from macrophages that reduce cholesterol accumulating in artery wall. Additionally, probucol also increased the cholesterol efflux capacity of hepatocytes, which accelerated liver cells excreting cholesterol into the bile and decreased circulating lipids level.

ABCA1 is an efflux transporter for cholesterol and phospholipids, which is essential for the formation of HDL. Tangier disease patients and $\mathrm{ABCA}^{-/-}$mice fail to form discoid or spherical HDL, which exhibit abnormal lipid deposition in various tissues [17]. In macrophages, ABCA1 facilitates the transfer of the cholesterol to apoA$\mathrm{I}$, and then the lipidated apoA-I/ABCA1 complex dissociate and release the nascent HDL [18]. In our research, we found that probucol up-regulated the expression of ABCA1 in macrophages. It indicated that probucol accelerated cholesterol effusing from macrophages by ABCA1, which might promote further releasing of nascent HDL that has much more strong binding capacity to cholesterol. In the liver cells, highly expression of liver ABCA1 is to facilitate biliary excretion of cholesterol, which plays an important role in lipid homeostasis [19]. We found that probucol also promoted cholesterol excreting through the bile by ABCA1, which played an important role in reducing circulating cholesterol.

SR-BI also plays an important role in HDL metabolism. The catabolism of HDL is regulated in part by cholesterol ester removal or delipidation by SR-BI, which can controls the structure, composition, and concentration of HDL [20]. We found that probucol up-regulated the expression of SR-BI in macrophages and accelerate cholesterol effusing from macrophages. Rigotti and colleagues reported that they found abnormally large, heterogeneous, apoE-enriched, HDL like particles in SRBI deficient mice, whose total serum cholesterol doubled [21]. Furthermore, the SR-BI deficiency greatly reduced the clearance of HDL cholesterol from serum [22]. Unfortunately, whether probucol reduce HDL-C levels by up-regulating expression of SR-BI in hepatocytes is unclearly. We found that probucol significantly increased expressions of SR-BI in hepatocytes. The increased SR-BI expression resulted in enhanced binding of large spherical HDL to the liver cells, which can speed up catabolism of HDL, and reduce serum HDL level. It may be the mechanism that probucol significant down-regulate HDL-C levels, but it didn't mean probucol declined HDL function, On the contrary it indicated probucol enhanced RCT and the metabolism of HDL.

HDL functions such as anti-oxidant and anti-inflammation are also important to restrain atherosclerosis. Native LDL has little effect on cells of the arterial wall, whereas oxidatively modified forms of LDL induce numerous proatherosclerotic effects [23]. HDL plays an important role in protecting against LDL oxidative modification, but dysfunctional HDL accumulates oxidants that promoting the formation of LDL-derived oxidized lipids and oxidation of LDL [24]. The enzyme PON1 plays the key role to the anti-oxidative effects of HDL. In our research, we found that rabbits treated by probucol have higher PON1 activity than atherosclerosis group. Navab and colleagues reported a failure of HDL to protect LDL from oxidation in patients with coronary atherosclerosis, which they proposed was due to their low serum PON1 activity despite relatively normal HDL-C levels [25]. PON1 can prevent lipid-peroxide accumulation on LDL and protect LDL from oxidative modification. Serum PON1 activity is lower in subjects prone to development of atherosclerosis such as in hypercholesterolemia disease [26]. Furthermore, some studies have proposed that PON1 may first associate 


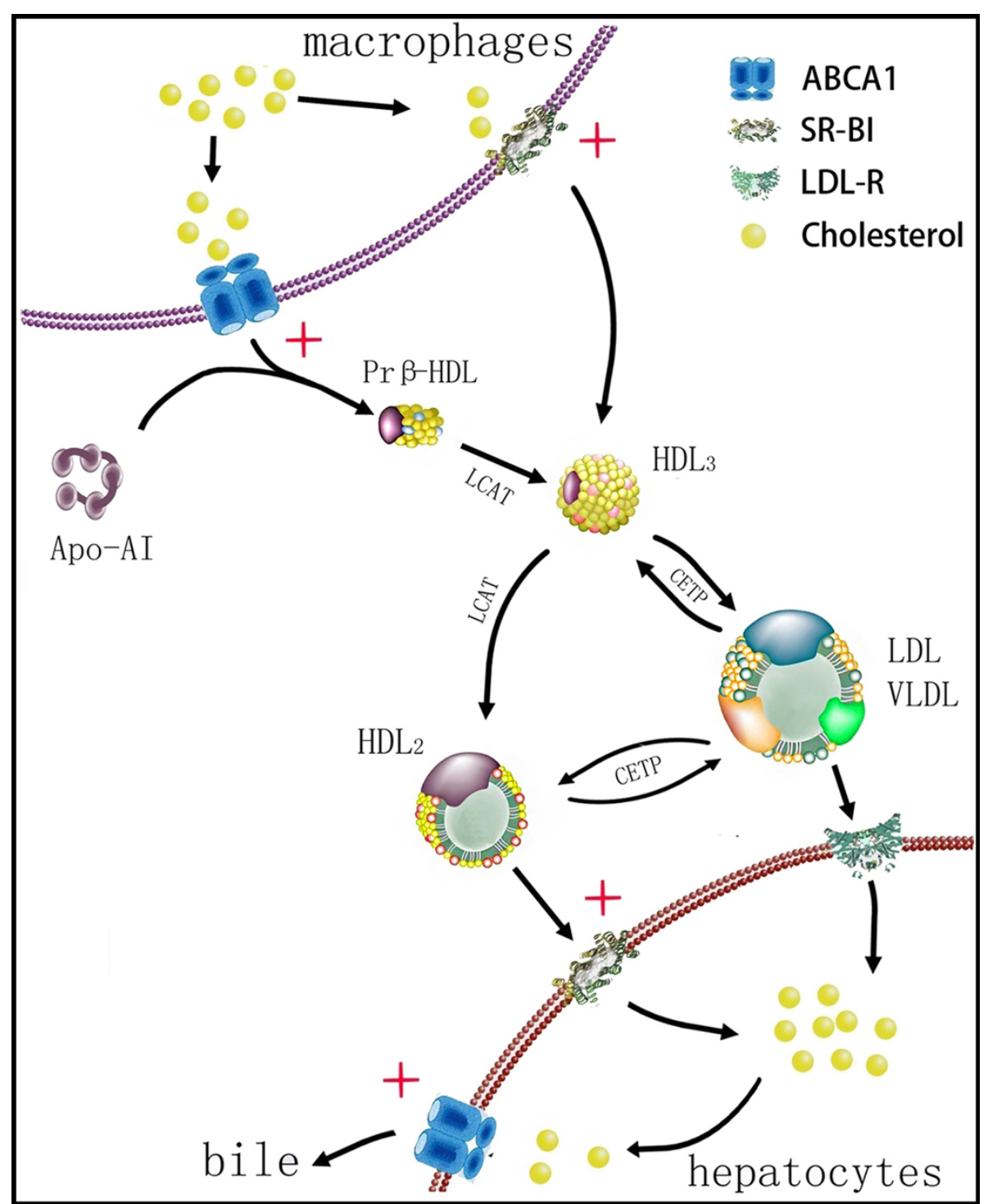

Figure 6 Process of RCT and HDL metabolism. Probucol up-regulate expression of ABCA1 and SR-B1 both in hepatocytes and peritoneal macrophages. (red+mean up-regulated the receptor expression)

with smaller $\mathrm{HDL}_{3}$, which are subsequently transformed into larger $\mathrm{HDL}_{2}$ particles. In this context, PON1 would be following the normal metabolic course of HDL in which remodelling leads to an increase in particle size, notably due to the accumulation of lipid components $[27,28]$. High PON1 activity may improve HDL anti-oxidant function.

Increasing evidences suggest that HDL is subjected to oxidation in lesion material that reverses the atheroprotective function [29]. In vitro studies demonstrated that MPO catalyzes oxidative modification of HDL leading to the development of dysfunctional proinflammatory and proatherogenic HDL [30]. MPO has been detected in human atherosclerotic lesions and high serum MPO is reported to be a risk factor for early adverse cardiac events in patients with acute coronary syndromes [31]. In addition, MPO was injected into mice led to significant reductions in RCT to the serum and fecal compartments, which demonstrating a direct effect of MPO on RCT in vivo[32]. In our research, we found probucol significantly decreased MPO activity, which in turn may reduce HDL oxidative modification and improve the process of RCT.

\section{Conclusions}

In summary, probucol increased the expression of ABCA1 and SR-BI in macrophages and hepatocytes, which speeded up the process of RCT. Furthermore, 
probucol improved HDL anti-oxidant function by increasing serum PON1 activity. Probucol also reduced oxidative and inflammatory modification of HDL by decreasing serum MPO activity. Probucol reduced HDL$\mathrm{C}$ level but improved HDL function and hindered the progression of atherosclerosis.

\section{Methods}

\section{Animal model}

Eighteen New Zealand white male rabbits (four months old, weighing $1.89 \mathrm{~kg} \sim 2.15 \mathrm{~kg}$ ) provided by the Laboratory Animal Centre of Southern Medical University and individually housed in air-conditioned room. After a 7day adaptation period, they were randomly divided into three groups: control group animals $(\mathrm{n}=6)$ were fed a regular diet for 12 weeks; the atherosclerosis group $(\mathrm{n}=$ 6) were fed a high fat diet supplemented with $1 \%(\mathrm{w} / \mathrm{w})$ cholesterol, $8 \%$ lard $(\mathrm{w} / \mathrm{w})$ and $0.05 \%$ cholate $(\mathrm{w} / \mathrm{w})$; and the probucol group were fed with the same high fat diet plus probucol $(400 \mathrm{mg} / \mathrm{kg} /$ day). Each rabbit consumed about $120 \mathrm{~g}$ of food daily. Rabbits were caged individually with water ad libitum for 12 weeks, and maintained on a 12 -h day/night cycle. Animal procedures were performed in accordance with guidelines set by the Animal Experiment Committee of Southern Medical University Guangzhou, China.

\section{Serum lipid, PON1 and MPO activity analyses}

Serum triglycerides (TG), total cholesterol (TC), lowdensity lipoprotein cholesterol (LDL-C) and HDL-C concentrations were measured with an automated biochemical analyzer (Type AU5421, Olympus, Japan) at the baseline and at the end of the study.

Serum PON1 activity was assayed with the method reported by Beltowski, using the synthetic substrate phenyl acetate (Sigma Co, American) [33]. PON1 activity towards phenyl acetate was determined by measuring the initial rate of substrate hydrolysis within the assay mixture $\left(3 \mathrm{~mL}\right.$ ) containing $2 \mathrm{mM}$ phenyl acetate, $2 \mathrm{mM} \mathrm{CaCl}_{2}$, and $10 \mu \mathrm{L}$ of plasma in $100 \mathrm{mM}$ Tris- $\mathrm{HCl}$ (pH 8.0). Absorbance was monitored for 90 seconds at $270 \mathrm{~nm}$ and enzyme activity was calculated from the $E_{270}$ of phenyl acetate $(1,310 / \mathrm{M} / \mathrm{cm}$ ) and expressed in $\mathrm{U} / \mathrm{mL}$ (where $1 \mathrm{U}$ of arylesterase hydrolyzes $1 \mu \mathrm{mol}$ of phenyl acetate/min).

MPO activity was measured by a MPO determination kit (Jiancheng Bioengineering Co) using commercially available reagents, according to the manufacturer's instructions. Briefly, the serum samples were incubated in a $50 \mathrm{mM}$ sodium phosphate buffer containing $1.5 \mathrm{M}$ hydrogen peroxide and $0.167 \mathrm{mmol} \mathrm{O}$-dianisidine dihydrochloride for $30 \mathrm{~min}$. The increase in absorbance at $460 \mathrm{~nm}$ was recorded with the use of a spectrophotometer and the Enzymatic activity was calculated from $\mathrm{E}_{460}=11300 / \mathrm{M} / \mathrm{cm}$. A unit of MPO activity is defined as the amount of enzyme degrading $1 \mu \mathrm{mol} \mathrm{H}_{2} \mathrm{O}_{2}$ per minute at $37^{\circ} \mathrm{C}$.

\section{Isolation of hepatocytes and peritoneal macrophages}

At the end of 12 weeks of the experiment, rabbits were anesthetized by $2 \%$ pentobarbital. Under sterile conditions, the parenchymal hepatocytes were isolated by classic in situ two steps perfusion of the liver with collagenase IV $(0.05 \%)$ by enzyme digestion with collagenase II $(2 \mathrm{mg} / \mathrm{ml})$. The peritoneal macrophages were collected by peritoneal lavage with $200 \mathrm{ml}$ PBS and purified by adherent method. Subsequently, using a modified method described by Zhao et al [34].

\section{Assay of HDL-mediated cholesterol efflux rate}

Experiments were performed as previously described [35]. Rabbit peritoneal macrophages and hepatocytes were respectively seeded in medium with $0.2 \%$ BSA and antibiotics cultured to $2 \times 10^{5}$ cells $/ \mathrm{ml}$. Subsequently, culture medium was replaced for $24 \mathrm{~h}$ with a medium containing $0.2 \% \mathrm{BSA}, 30 \mu \mathrm{g} / \mathrm{ml} \mathrm{Ox}-\mathrm{LDL}$, and $1 \mu \mathrm{Ci} / \mathrm{ml}$ $\left[1 \alpha, 2 \alpha-{ }^{3} \mathrm{H}\right]$-cholesterol (Perkin-Elmer) in DMEM/F12. After cholesterol loading, cells were washed twice with serum-free medium. Cells were incubated in DMEM/F12 with CAMP $(0.3 \mathrm{mmol} / \mathrm{L})$ for the next $12 \mathrm{~h}$. And then, apoA-I $(10 \mathrm{ug} / \mathrm{ml})$ was added to promote free cholesterol efflux for $4 \mathrm{~h}$. the incubation medium was collected and centrifuged before counting radioactivity. The cell monolayer was washed with PBS and lysed with $1 \mathrm{ml}$ of $\mathrm{NaOH}$ $(0.1 \mathrm{~mol} / \mathrm{L})$. The radioactivity of medium and cell lysates was measured by liquid scintillation spectrometry (Beckman Instruments, Inc.). The cholesterol efflux rate was expressed as the medium $\left[{ }^{3} \mathrm{H}\right]$ cholesterol radioactivity as a percentage of total $\left[{ }^{3} \mathrm{H}\right]$ cholesterol radioactivity (cells plus medium). Individual efflux values were calculated as the averages of 3 determinations in different wells.

\section{Analyses of ABCA1 and SR-BI mRNA in liver by real-time PCR}

Liver tissue was snap-frozen in liquid nitrogen until RNA extraction. Tissues were then powdered in liquid nitrogen. The quantitative analyses of ABCA1 and SR-B1 mRNA level on rabbit liver tissues were performed by quantitative real-time polymerase chain reaction (RT-PCR).Total RNA was extracted from the frozen liver tissues by using RNA Trizol reagent (Gibco RRL, Gaithersburg, USA). Then first-strand cDNA was synthesized by using PrimeScript RT Reagent Kit (Takara, China) according to the instruction from manufacture. The quantitative RT-PCR was performed on iQ5 Real Time PCR Detection System (BioRad, American) using AllinOne ${ }^{\mathrm{TM}} \mathrm{Q}-\mathrm{PCR}$ Mix (GeneCopoeia Inc, American). Expression levels of the target genes generated standard curves were normalized against an endogenous reference gene glyceraldehydes 3-phosphate 
dehydrogenase (GAPDH). The specific primer sequences were listed in the following pattern: (1) ABCA1: forward primer: 5'-GAT GGC AAT CAT GGT CAA TGG -3', reverse primer: 5 -AGC TGG TAT TGT AGC ATG TTC CG-3' yielding a 201-bp size product; (2) SR-BI: forward primer: 5'-CAG TGG GCA TTG TGT CCT GTC -3', reverse primer: 5'-GGC TCA GTG CAG GCT GAT GTC-3' yielding a 286-bp size product; and (3) GAPDH: forward primer: 5'-GGA GCC AAA AGG GTC ATC-3', reverse primer: 5'-CCA GTG AGT TTC CCG TTC-3' yielding a 346-bp size product. PCRs for each sample were performed in duplicate, and the relative gene expressions were analyzed as described previously [36].

\section{Analyses of ABCA1 and SR-BI protein expression by flow cytometer}

The protein assay of ABCA1 and SR-B1 in peritoneal macrophages and hepatocytes were performed as previously described by Pirillo et al [37]. The suspension of peritoneal macrophages and hepatocytes were respectively mixed with the antibody of ABCA1 or SR-B1(Santa Cruz Biontechnology, Inc) for $60 \mathrm{~min}$ at room temperature in the test tubes. The mixture was then washed two times with PBS and added the antibody labelled PE fluorescence (Seretec, Inc). After 30 min ABCA1/ SR-B1exprssion was measured by flow cytometer (BD FACSCalibur) and expressed as an average level in every hundred detected cells.

\section{Quantification of aortic atherosclerosis, histology and immunohistochemistry}

All segments were embeded in paraffin and cut into 4- $\mu \mathrm{m}$ cross sections and stained with hematoxylin and eosin (H\&E) for histological examination. The percentage plaque area, which was defined as surface area of plaque/surface area of whole intima, and the aortic intima-media thickness (IMT) were calculated for evaluating the degree of aortic atherosclerosis.

Experiments were performed as previously described [38]. Immunostaining for ABCA1 (Boster Biotechnology Co. Ltd China) and SR-BI (Abcam Co.Ltd American) was performed in paraffin-embedded Aortic atherosclerosis sections using the specific antibody and a Strept AvidinBiotin Complex (SABC) Antibody binding was visualized with SABC kits (Boster Biotechnology Co. Ltd), Diaminobenzidine (DAB) and 3-Amino-9-Ethylcarbazole (AEC) were used as the chromogen and Mayer's hematoxylin as the nuclear counterstain. The sections were dehydrated, cleared, mounted and performed by morphometric analysis. All sections (H\&E and immunostained) for microscopic quantification were captured under an Olympus BX51 light microscope equipped with a DP70 digital camera (Olympus, Tokyo, Japan) and were measured with Image pro plus 6.0 special image analysis software (Media Cybernetics Co, American).

\section{Statistical analysis}

Data are presented as mean \pm S.E.M. A one-way ANOVA was used for analyzing differences in variables between groups at the same time point. When $P$ was $\leq 0.05$, the least significant difference method was used for comparison. An independent sample t-test was used for analyzing the differences in variables between two groups at the same time point. SPSS 13.0 software was used for statistical analysis with $\mathrm{P}<0.05$ indicating a statistically significant difference.

\section{Abbreviations}

HDL-C : High density lipoprotein cholesterol; LDL-C Low-density lipoprotein cholesterol; VLDL : Low-density lipoprotein cholesterol; TC : total cholesterol; TG : Triglyceride; PON1 : Paraoxonase 1; MPO : Myeloperoxidase; RT-PCR : Real-Time Reverse transcription polymerase chain reaction; FACS : flow cytometer; ABCA1 : ATP binding cassette transporter A1; SR-BI : scavenger receptor class $B$ type l; IMT : intima media thickness; CHD : Cardiovascular heart disease; Apo-AI : apolipoprotein-Al; CETP : cholesteryl ester transfer protein; LCAT : lecithin cholesterol acyl transferase; $\mathbf{R C T}$ : reverse cholesterol transport.

\section{Acknowledgements}

This work was supported by the Guangdong Scientific and Technological Grant (No. 2008B030301158) and the key foundation of Nanfang Hospital (No. 2008A003).

\section{Authors' contributions}

ZGG was responsible for the experimental design, supervising the project, data analysis and revising the manuscript. JKZ carried out all aspects of experiments, data analysis and drafted the manuscript. CL was involved in pathohistology, immunoassays and all samples collected. ZKW participated in Constructed Animal models, collected blood sample, assayed cholesterol efflux rate and RT-PCR. YWL, YT were involved in Cell culture, flow cytometer and supervising the project. All authors read and approved the final manuscript.

\section{Competing interests}

The authors declare that they have no competing interests.

Received: 2 October 2011 Accepted: 12 November 2011 Published: 12 November 2011

\section{References}

1. National Cholesterol Education Program (NCEP) Expert Panel on Detection, Treatment of High Blood Cholesterol in Adults (Adult Treatment Panel III): Third Report of the National Cholesterol Education Program (NCEP) Expert Panel on Detection, Evaluation, and Treatment of High Blood Cholesterol in Adults (Adult Treatment Panel III) final report. Circulation 2002, 106:3143-3421.

2. Franceschini G: Epidemiologic evidence for high-density lipoprotein cholesterol as a risk factor for coronary artery disease. Am J Cardiol 2001, 88(12):9N-13N.

3. Gomaraschi M, Baldassarre D, Amato M, Eligini S, Conca P, Sirtori CR, Franceschini G, Calabresi L: Normal vascular function despite low levels of high-density lipoprotein cholesterol in carriers of the apolipoprotein A-I (Milano) mutant. Circulation 2007, 116:2165-2172.

4. Barter PJ, Caulfield M, Eriksson M, Grundy SM, Kastelein JJP, Komajda M, Sendon JL, Mosca L, Tardif JC, Waters DD, Shear CL, Revkin JH, Buhr KA Fisher MR, Tall AR, Brewer B: Effects of Torcetrapib in Patients at High Risk for Coronary Events. N Engl J Med 2007, 357:2109-2122. 
5. Hausenloy DJ, Yellon DM: Targeting residual cardiovascular risk: raising high-density lipoprotein cholesterol levels. Postgrad Med J 2008, 84(997):590-598.

6. Yamashita S, Matsuzawa Y: Where are we with probucol: a new life for an old drug? Atherosclerosis 2009, 207(1):16-23.

7. Tardif JC, Cote G, Lesperance J, Bourassa M, Lambert J, Doucet S, Bilodeau L, Nattel S, Guise P: Probucol and multivitamins in the prevention of restenosis after coronary angioplasty. N Engl J Med 1997, 337:365-732.

8. Yamashita S, Hbujo H, Arai H, Harada-Shiba M, Matsui S, Fukushima M, Saito Y, Kita T, Matsuzawa Y: Long-term probucol treatment prevents secondary cardiovascular events: a cohort study of patients with heterozygous familial hypercholesterolemia in Japan. J Atheroscler Thromb 2008, 15(6):292-303.

9. Hazen S: HDL structure, function, therapeutics, and imaging. Arterioscler Thromb Vasc Biol 2010, 30(2):138.

10. Tsompanidi EM, Brinkmeier MS, Fotiadou EH, Giakoumi SM, Kypreos KE: $\mathrm{HDL}$ biogenesis and functions: Role of HDL quality and quantity in atherosclerosis. Atherosclerosis 2010, 208(1):3-9.

11. Vekic J, Kotur-Stevuljevic J, Jelic-Ivanovic Z, Spasic S, SpasojevicKalimanovska V, Topic A, Zeljkovic A, Stefanovic A, Zunic G: Association of oxidative stress and PON1 with LDL and HDL particle size in middleaged subjects. Eur J Clin Invest 2007, 37(9):715-723.

12. Heinecke JW: The role of myeloperoxidase in $\mathrm{HDL}$ oxidation and atherogenesis. Curr Atheroscler Rep 2007, 9(4):249-251.

13. Duffy $D$, Rader DJ: Update on strategies to increase HDL quantity and function. Nat Rev Cardiol 2009, 6(7):455-463.

14. Movva R, Rader DJ: Laboratory assessment of HDL heterogeneity and function. Ann Biol Clin (Paris) 2009, 67(1):7-21.

15. Kontush A, Chapman MJ: Functionally defective high-density lipoprotein: a new therapeutic target at the crossroads of dyslipidemia, inflammation, and atherosclerosis. Pharmacol Rev 2006, 58(3):342-374.

16. Movva R, Rader DJ: Laboratory assessment of HDL heterogeneity and function. Ann Biol Clin (Paris) 2009, 67(1):7-21.

17. Hiroshi N: Latest Insights into High Density Lipoprotein Functions. The Endocrinologist 2009, 19(4):179-186.

18. Orsó E, Broccardo C, Kaminski WE, Böttcher A, Liebisch G, Drobnik W, Götz A, Chambenoit O, Diederich W, Langmann T, Spruss T, Luciani MF, Rothe G, Lackner KJ, Chimini G, Schmitz G: Transport of lipids from golgi to plasma membrane is defective in tangier disease patients and Abc1deficient mice. Nat Genet 2000, 24(2):192-196.

19. Neufeld EB, Stonik JA, Demosky SJ Jr, Knapper CL, Combs CA, Cooney A, Comly M, Dwyer N, Blanchette-Mackie J, Remaley AT, Santamarina-Fojo S, Brewer HB Jr: The ABCA1 transporter modulates late endocytic trafficking: insights from the correction of the genetic defect in Tangier disease. J Biol Chem 2004, 279(15):15571-15578.

20. Cavelier LB, Qiu Y, Bielicki JK, Afzal V, Cheng JF, Rubin EM: Regulation and activity of the human ABCA1 gene in transgenic mice. J Biol Chem 2001, 276(21):18046-18051

21. Zannis VI, Chroni A, Krieger M: Role of apoA-I, ABCA1, LCAT, and SR-BI in the biogenesis of HDL. J Mol Med 2006, 84(4):276-294

22. Liadaki KN, Liu T, Xu S, Ishida BY, Duchateaux PN, Krieger JP, Kane J, Krieger M, Zannis VI: Binding of high density lipoprotein (HDL) and discoidal reconstituted $\mathrm{HDL}$ to the $\mathrm{HDL}$ receptor scavenger receptor class B type I. Effect of lipid association and APOA-I mutations on receptor binding. J Biol Chem 2000, 275(28):21262-21271.

23. Rigotti A, Trigatti BL, Penman M, Rayburn H, Herz J, Krieger M: A targeted mutation in the murine gene encoding the high density lipoprotein (HDL) receptor scavenger receptor class B type I reveals its key role in HDL metabolism. Proc Natl Acad Sci USA 1997, 94(23):12610-12615.

24. Out R, Hoekstra M, Spijkers JA, Kruijt JK, van Eck M, Bos IS, Twisk J, Van Berkel TJ: Scavenger receptor class B type I is solely responsible for the selective uptake of cholesteryl esters from HDL by the liver and the adrenals in mice. J Lipid Res 2004, 45(11):2088-2095.

25. Mackness Ml, Durrington PN: HDL, its enzymes and its potential to influence lipid peroxidation. Atherosclerosis 1995, 115(2):243-253.

26. Kontush A, Chantepie S, Chapman MJ: Small, dense HDL particles exert potent protection of atherogenic LDL against oxidative stress. Arterioscler Thromb Vasc Biol 2003, 23(10):1881-1888.
27. Mackness B, Durrington PN, Boulton AJ, Hine D, Mackness MI: Serum paraoxonase activity in patients with type 1 diabetes compared to healthy controls. Eur J Clin Invest 2002, 32(4):259-264.

28. Navab M, Hama-Levy S, Van Lenten BJ, Fonarow GC, Cardinez CJ, Castellani LW, Brennan ML, Lusis AJ, Fogelman AM, La Du BN: Mildly oxidized LDL induces an increased apolipoprotein J/paraoxonase ratio. J Clin Invest 1997, 99(8):2005-2019.

29. Rye KA, Clay MA, Barter PJ: Remodelling of high density lipoproteins by plasma factors. Atherosclerosis 1999, 145(2):227-238.

30. K Nicholls SJ, Zheng L, Hazen SL: Formation of dysfunctional high-density lipoprotein by myeloperoxidase. Trends Cardiovasc Med 2005, 15(6):212-219.

31. Niu X, Zammit V, Upston JM, Dean RT, Stocker R: Coexistence of oxidized lipids and alpha-tocopherol in all lipoprotein density fractions isolated from advanced human atherosclerotic plaques. Arterioscler Thromb Vasc Biol 1999, 19(7):1708-1718.

32. Zheng L, Nukuna B, Brennan ML, Sun M, Goormastic M, Settle M, Schmitt D, Fu X, Thomson L, Fox PL, Ischiropoulos H, Smith JD, Kinter M, Hazen SL: Apolipoprotein A-I is a selective target for myeloperoxidase-catalyzed oxidation and functional impairment in subjects with cardiovascular disease. J Clin Invest 2004, 114(4):529-541.

33. Beltowski J, Jamroz-Wisniewska A, Borkowska E, Wójcicka G: Differential effect of antioxidant treatment on plasma and tissue paraoxonase activity in hyperleptinemic rats. Pharmacol Res 2005, 51(6):523-532.

34. Zhao SP, Yang J, Li J, Dong SZ, Wu ZH: Effect of niacin on LXRalpha and PPARgamma expression and HDL-induced cholesterol efflux in adipocytes of hypercholesterolemic rabbits. Int J Cardiol 2008, 124(2):172-178.

35. Troutt JS, Alborn WE, Mosior MK, Dai J, Murphy AT, Beyer TP, Zhang Y, Cao G, Konrad RJ: An apolipoprotein A-I mimetic dose-dependently increases the formation of prebeta1 HDL in human plasma. J Lipid Res 2008, 49(3):581-587.

36. Livak KJ, Schmittgen TD: Analysis of relative gene expression data using real-time quantitative PCR and the 2(-Delta Delta C(T)) Method. Methods 2001, 25(4):402-408.

37. Pirillo A, Uboldi P, Kuhn H, Catapano AL: 15-Lipoxygenase-mediated modification of high-density lipoproteins impairs SR-BI- and ABCA1dependent cholesterol efflux from macrophages. Biochim Biophys Acta 2006, 1761(3):292-300.

38. Speidl WS, Cimmino G, Ibanez B, Elmariah S, Hutter R, Garcia MJ, Fuster V Goldman ME, Badimon JJ: Recombinant apolipoprotein A-I Milano rapidly reverses aortic valve stenosis and decreases leaflet inflammation in an experimental rabbit model. Eur Heart J 2010, 31(16):2049-2057.

doi:10.1186/1476-511X-10-210

Cite this article as: Zhong et al:: Probucol alleviates atherosclerosis and improves high density lipoprotein function. Lipids in Health and Disease 2011 10:210.

\section{Submit your next manuscript to BioMed Central and take full advantage of:}

- Convenient online submission

- Thorough peer review

- No space constraints or color figure charges

- Immediate publication on acceptance

- Inclusion in PubMed, CAS, Scopus and Google Scholar

- Research which is freely available for redistribution 